\title{
Sub-nanosecond Infrared Photodetection using III-V Colloidal Quantum Dots
}

\section{Bin Sun}

University of Toronto https://orcid.org/0000-0002-8233-0999

\section{Amin morteza najarian}

University of Toronto https://orcid.org/0000-0002-0455-0451

\section{Chao Zheng}

University of Toronto

\section{Laxmi Sagar}

University of Toronto

\section{Min-Jae Choi}

University of Toronto

\section{Xiyan Li}

Department of Electrical and Computer Engineering University of Toronto 35 St George Street Toronto Ontario M5S 1A4 Canada.

\section{Larissa Levina}

Department of Electrical and Computer Engineering University of Toronto 35 St George Street Toronto Ontario M5S 1A4 Canada.

\section{Se-Woong Baek}

University of Toronto

\section{Seungjin Lee}

University of Toronto

\section{Ahmad R. Kirmani}

National Institute of Standards and Technology (NIST)

\section{Jehad Abed}

University of Toronto https://orcid.org/0000-0003-1387-2740

\section{Mengxia Liu}

University of Toronto

\section{Peicheng Li}

University of Toronto

\section{Lee Richter}

National Institute of Standards and Technology (NIST)

\section{Oleksandr Voznyy}

University of Toronto Scarborough https://orcid.org/0000-0002-8656-5074

\section{Zheng-Hong Lu}


University of Toronto https://orcid.org/0000-0003-2050-0822

\section{F. Pelayo Garcia de Arquer}

University of Toronto https://orcid.org/0000-0003-2422-6234

Edward Sargent ( $\nabla$ ted.sargent@utoronto.ca)

University of Toronto https://orcid.org/0000-0003-0396-6495

\section{Letter}

Keywords: Slow Charge Extraction, Low Permittivity, Covalent Character, Surface Management, Amphoteric Ligand Coordination, External Quantum Efficiency

Posted Date: November 20th, 2020

DOl: https://doi.org/10.21203/rs.3.rs-92318/v1

License: (c) (i) This work is licensed under a Creative Commons Attribution 4.0 International License. Read Full License 


\section{Sub-nanosecond Infrared Photodetection using III-V Colloidal Quantum Dots}

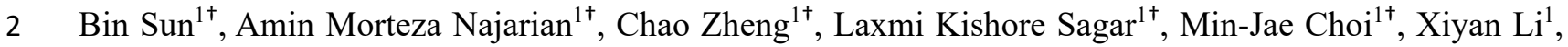

3 Larissa Levina ${ }^{1}$, Se-Woong Baek ${ }^{1}$, Seungjin Lee ${ }^{1}$, Ahmad R. Kirmani ${ }^{2 *}$, Jehad Abed ${ }^{1}$, Mengxia Liu ${ }^{1}$,

4 Peicheng $\mathrm{Li}^{3}$, Lee J. Richter ${ }^{2}$, Oleksandr Voznyy ${ }^{1}$, Zheng Hong Lu ${ }^{3}$, F. Pelayo García de Arquer ${ }^{1 * *}$ and

5 Edward H. Sargent ${ }^{\text {*** }}$

$6 \quad{ }^{1}$ Department of Electrical and Computer Engineering, University of Toronto, Toronto, Ontario M5S 1A4,

7 Canada

$8{ }^{2}$ Materials Science and Engineering Division, National Institute of Standards and Technology (NIST),

9 Gaithersburg, MD 20899, USA

${ }^{3}$ Department of Material Science and Engineering, University of Toronto, 184 College St, Toronto, ON M5S 3E4, Canada

\section{${ }^{*}$ Guest researcher}

*e-mail: pelayo.garciadearquer@utoronto.ca; ted.sargent@utoronto.ca

${ }^{\dagger}$ These authors contributed equally.

Abstract: Colloidal quantum dots (CQDs) are promising materials for IR light detection due to their tunable bandgap and solution processing; but to date, the time response of CQD IR photodiodes has been inferior to that provided by Si and InGaAs. We reasoned that the high permittivity of II-VI CQDs leads to slow charge extraction due to screening and capacitance; whereas III-Vs - if their surface chemistry could be mastered - offer a strong covalent character for low permittivity and fast operation. In initial studies, we found that existing covalent character led to imbalanced charge transport in InAs, the result of unpassivated surfaces and uncontrolled heavy doping. We report surface management using amphoteric ligand coordination and find that it addresses simultaneously the In and As surface dangling bonds. The new InAs CQD solids combine high mobility $\left(0.04 \mathrm{~cm}^{2} \mathrm{~V}^{-1} \mathrm{~s}^{-1}\right)$ with a $4 \mathrm{x}$ reduction in permittivity compared to $\mathrm{PbS}$ CQDs. The resulting photodiodes achieve a response time faster than $300 \mathrm{ps}-\mathrm{a}$ more than $100 \mathrm{x}$ improvement compared to the best previously-reported CQD photodiodes - combined with an external quantum efficiency (EQE) of $30 \%$ at $940 \mathrm{~nm}$. 
Infrared photodetection underpins applications in medicine and bioimaging, information technology, machine vision, and security ${ }^{1,2}$. Emerging technologies such as autonomous driving and augmented reality rely on Light Detection and Ranging (LiDAR) based on time of flight (ToF) ${ }^{3}$. This requires sensitive and ultrafast photodetection of infrared light with sub-ns resolution ${ }^{4}$. Today, this is achieved in the nearinfrared (NIR) using indirect bandgap silicon detectors - limited by silicon's low absorption coefficientand, at longer wavelengths, using epitaxially-grown semiconductors such as III- $\mathrm{Vs}_{\mathrm{s}}$ and $\mathrm{Hg}_{1-\mathrm{x}} \mathrm{Cd}_{\mathrm{x}} \mathrm{Te}^{5,6}$.

Colloidal quantum dots (CQDs) are of interest by their low-temperature solution processing, which allows them to be integrated in post-processing with a silicon electronics front-end ${ }^{7-10}$. Their bandgap is size-tuned over a wide range of wavelengths. $\mathrm{PbS}$, for example, has a widely-programmable absorption onset covering the visible and short-wavelength infrared (SWIR) ${ }^{11,12}$; however, its high permittivity, stemming from its ionic character $-\varepsilon_{\mathrm{r}}=180$ for bulk $\mathrm{PbS}^{13}$ - slows charge extraction both for bulk ${ }^{14}$ and CQD photodiodes ${ }^{15}$ due to screening and capacitance effects.

Indium arsenide (InAs) CQDs can be tuned in a similar spectral range as PbS CQDs, and offer the prospective advantage of a covalent lattice and hence lower permittivity ${ }^{16,17}$. This, however, comes with a challenge: the surface in InAs CQDs is charge-imbalanced, leading to poor passivation and heavy doping, as surface states pin the Fermi level near the conduction band minimum. Much effort has been paid to improving mobility by decreasing interdot distance via ligand exchanges and surface treatments in CQD solids $^{18,19}$, but III-V CQDs require a new approach in order to neutralize CQD charge surface states and reduce trap density.

Trap states in InAs semiconductors originate from surface In and As dangling bonds ${ }^{20}$. Growing epitaxially-matched inorganic shells on CQDs passivates surface defects, but it hinders CQD coupling and carrier transport ${ }^{21,22}$. Using molecular metal chalcogenide complexes (MCCs, e.g. $\mathrm{Sn}_{2} \mathrm{~S}_{6}{ }^{4-}$ and $\mathrm{In}_{2} \mathrm{Se}_{4}{ }^{2-}$ ) enhances carrier mobility in III-V CQD solids, leading to an impressive mobility of $15 \mathrm{~cm}^{2} \mathrm{~V}^{-1} \mathrm{~s}^{-}$ ${ }^{1}$, but introduces undesired in-gap states ${ }^{19,23}$. Etching As sites using strong acids facilitates In-site passivation but leads to low mobility $\left(10^{-3} \mathrm{~cm}^{2} \mathrm{~V}^{-1} \mathrm{~s}^{-1}\right)^{18,20,24}$. 
Here we present a new surface passivation strategy that addresses charge imbalance and passivation in InAs CQD solids for infrared photodetectors. We introduced $\mathrm{InBr}_{3}$ passivants to replace native insulating oleic acid ligands, thereby providing surface passivation and charge transport simultaneously. We found that $\mathrm{InBr}_{3}$ is amphoteric, dissociating into an X-type ligand ( $\left.\mathrm{Br}^{-}\right)$that passivates In dangling bonds; and into a Z-type $\left(\mathrm{InX}_{2}{ }^{+}\right)$ligand $^{25}$ that passivates As dangling bonds. We incorporate N,N-dimethylformamide (DMF) as a coordinating agent to stabilize otherwise unstable $\mathrm{Br}^{-}$and $\mathrm{InX}_{2}{ }^{+}$passivants. We assess the copassivated InAs surfaces using a suite of spectroscopies and density functional theory (DFT) calculations. The resulting $\mathrm{InBr}_{3}$-InAs CQD solids achieve a mobility value of $0.04 \mathrm{~cm}^{2} \mathrm{~V}^{-1} \mathrm{~s}^{-1},>10$ times higher than in halide-exchanged InAs solids ${ }^{18}$; and a low dielectric constant of 6.3 - a near $4 \mathrm{x}$ advance compared to $\mathrm{PbS}$ CQD solid counterparts. The corresponding photodiode devices achieve a $30 \%$ external quantum efficiency (EQE), a responsivity of $0.22 \mathrm{~A} \mathrm{~W}^{-1}$, and measured detectivity of $10^{11} \mathrm{cmHz}^{1 / 2} \mathrm{~W}^{-1}$ at the excitonic peak $(940 \mathrm{~nm})$. Ultrafast transient photocurrent (TPC) experiments reveal a fall time of $300 \mathrm{ps,}$ equivalent of $>1 \mathrm{GHz}$ bandwidth. This is the first demonstration of efficient III-V CQD photodiodes and the fastest solution-processed infrared photodiode reported, with over a 100-fold improvement compared to the best CQDs photodiodes ${ }^{15,26}$.

68

69

70

71
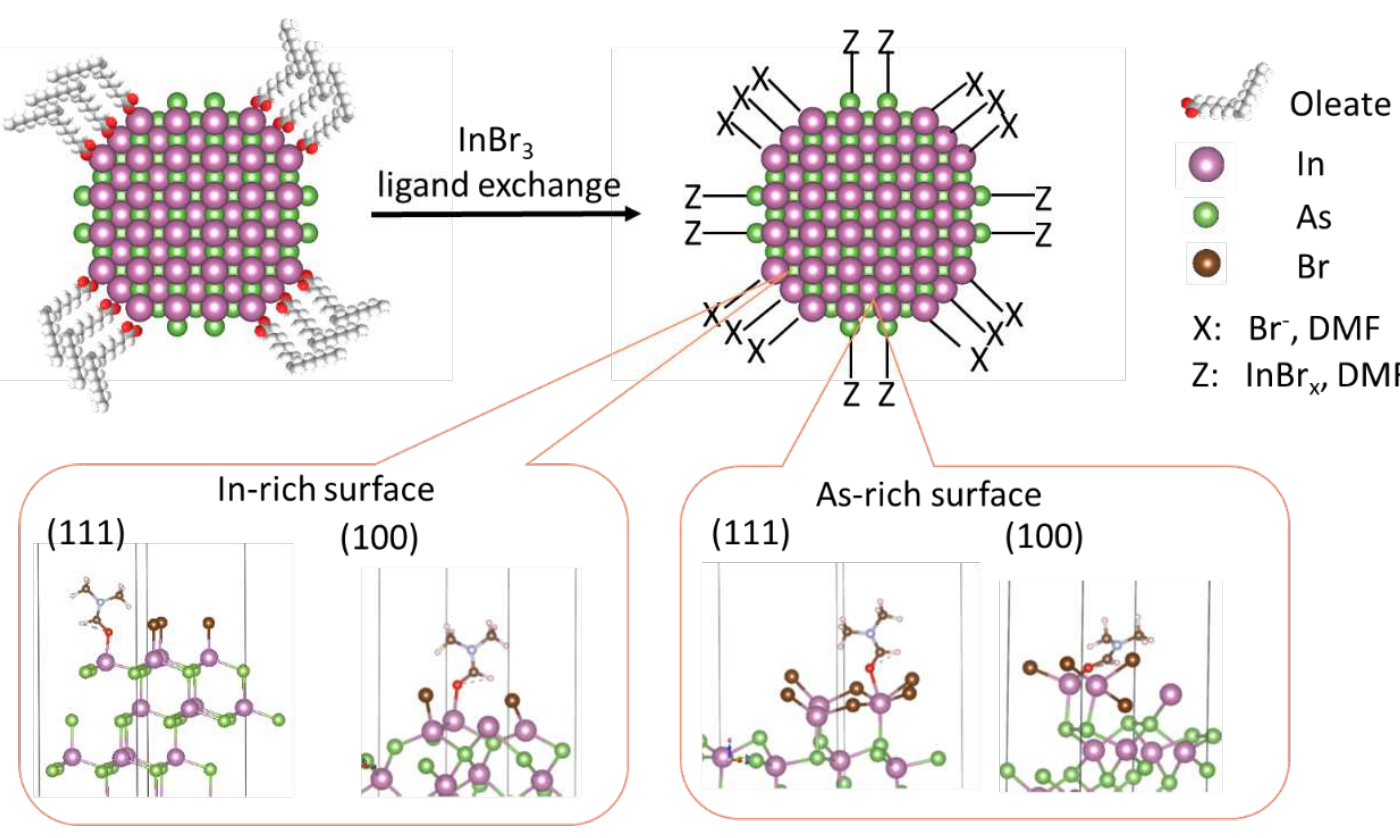

$\mathrm{X}: \mathrm{Br}^{-}, \mathrm{DMF}$

Z: $\operatorname{InBr}$, DMF

(111)

As-rich surface

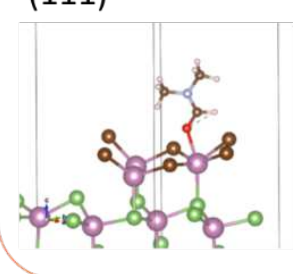

(100)

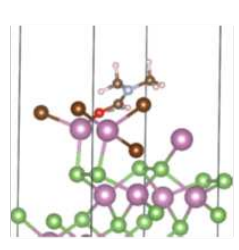

Fig. 1 | Stabilization of InAs CQDs. Scheme of $\mathrm{InBr}_{3}$ ligand exchange and InAs quantum dot surface configuration according to DFT calculations: a larger stabilization energy was observed by adding DMF coordination in the system for both In-rich and As-rich surfaces. 
We first synthesized InAs CQDs (semisphere, Supplementary Fig. 1) using a modified approach via the continuous injection ${ }^{27,28}$. As-synthesized InAs CQDs are capped by insulating oleic acid ligands, which need to be removed for electrical coupling. The oleic acid capped InAs (OA-InAs) in octane show low photoluminescence quantum yield (PLQY $<1 \%)^{27}$, which we attribute to the presence of surface defects as negatively charged As dangling bonds ${ }^{29}$ that are not passivated using oleic acid.

To increase understanding of the nature and role of the dangling bonds (DBs) and guide in the design of a surface exchange strategy to passivate InAs surfaces, we studied the zinc-blende InAs structure using DFT calculations and estimated the thermodynamic stability of their surfaces (see Supplementary text). The crystal facets exposed, including (111) and (100), are polar and terminated with positively charged In and negatively charged As.

The nature of zinc-blende InAs structure demands the simultaneous passivation of both In and As dangling bonds for efficient ambipolar optoelectronics - i.e. for high performance in devices whose operation relies on electrons and holes simultaneously, as distinct from unipolar devices such as fieldeffect transistors (FETs). The success of X-type on positively charged surfaces suggests ${ }^{30}$ that halides could be promising candidates for In passivation. Z-type ligands binding as a neutral two-electron acceptor (a Lewis acid) have been demonstrated to passivate phosphide deep traps leading to enhanced photoluminescence efficiency ${ }^{31}$. This prompted us to design a dual passivation strategy that would seek to address In and As dangling bonds using X-type and Z-type ligands, respectively.

We hypothesized that metal halide salts such as $\mathrm{InBr}_{3}$ could be candidates for this as when dissolved in certain polar solvents such as DMF, they would dissociate into the needed X-type (Br-) and Z-type $\left(\operatorname{InBr}_{2}{ }^{+}\right)$) ligands ${ }^{25}$. To assess the potential of these ions as co-passivants, we performed DFT calculations on different InAs surfaces (see Suppl. Info for details). The calculation results indicate that $\mathrm{Br}^{-}$passivates In-terminated surfaces whereas $\operatorname{InBr}_{2}{ }^{+}$addresses As-terminated surfaces (Supplementary Fig. 2, 3, and 4).

Based on these calculations, we designed a one-step, two-phase solution exchange method to replace OA long ligands with $\mathrm{InBr}_{3}$ salts assisted by ammonium acetate (AA), which enables the removal of the original long organic ligands $(\mathrm{OA})^{32}$. Before the ligand exchange, InAs CQDs are dispersed in octane and $\mathrm{InBr}_{3}\left(0.1 \mathrm{~mol} \mathrm{~L}^{-1}, 0.18 \mathrm{~g}\right.$ in $\left.5 \mathrm{~mL}\right)$ and AA $\left(0.04 \mathrm{~mol} \mathrm{~L}^{-1}, 0.023 \mathrm{~g}\right.$ in $\left.5 \mathrm{~mL}\right)$ are pre-dissolved in DMF. During the exchange, InAs CQDs transfer from nonpolar octane layer to polar DMF solution, which indicates that long OA ligands are replaced by $\mathrm{InBr}_{\mathrm{x}}$ ligands. 

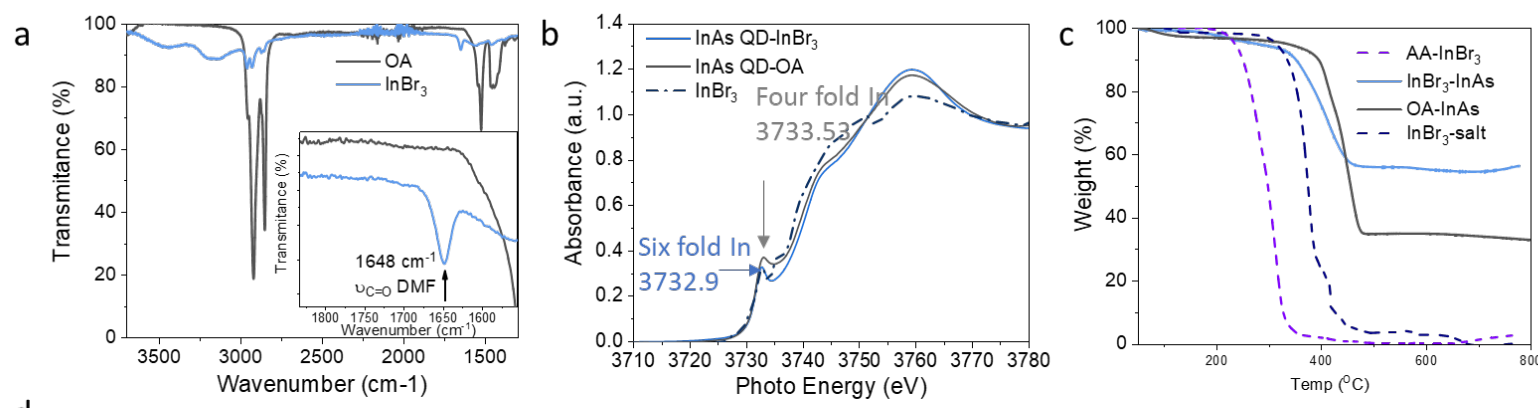

d
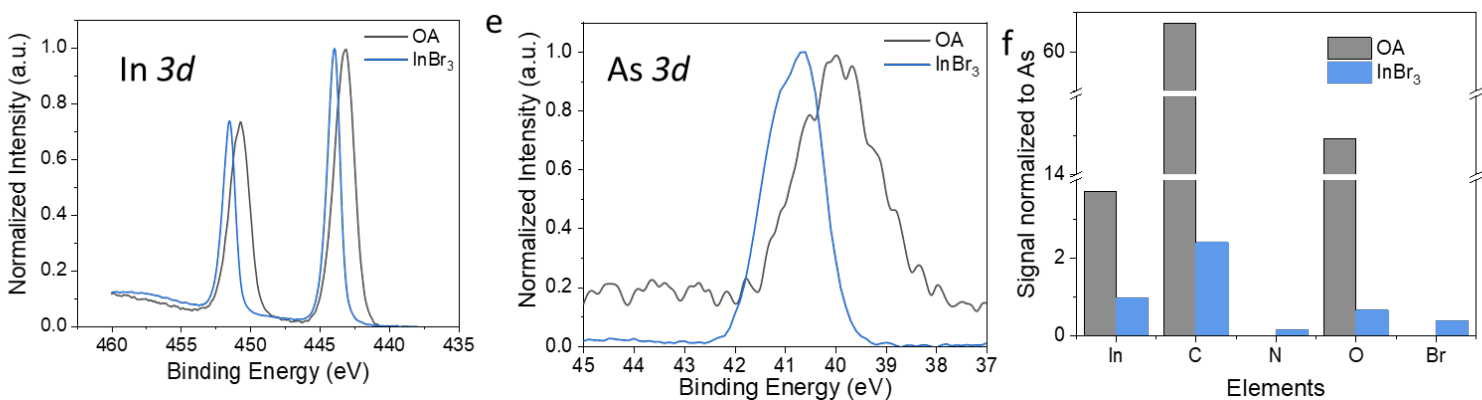

Fig. 2 | Investigation of passivation using InBr 3 -DMF complexes. a, Attenuated total reflection (ATR) FTIR of InAs CQD films before and after $\mathrm{InBr}_{3}$ ligand exchange on glass. $\mathbf{b}$, In $\mathrm{L}_{3}$-edge XANES spectra of InAs CQD films and $\mathrm{InBr}_{3}$ films (spin-coated from DMF solution) on Si wafer. c, Thermogravimetric analysis (TGA) of InAs CQDs and $\operatorname{InBr}_{3}$ salt with/without AA samples. d, In 3d X-ray photoelectron spectroscopy (XPS) signal. e, As 3d XPS signal. f, Elemental ratio of InAs CQD films before and after $\operatorname{InBr}_{3}$ ligand exchange.

To track the removal of long ligands in the exchanged film, we carried out Fourier transform infrared spectroscopy (FTIR) measurements (Fig. 2a). OA-InAs CQDs show typical CH resonances at $\sim 2900 \mathrm{~cm}^{-1}$ and $\mathrm{C}=\mathrm{O}$ vibrations owing to $\mathrm{OA}$ on $\mathrm{CQD}$ surface at $\sim 1540 \mathrm{~cm}^{-1}$. After the ligand exchange, the OA signals disappear. The $\mathrm{C}=\mathrm{O}$ signal at $\sim 1640 \mathrm{~cm}^{-1}$ is attributed to DMF complexes, which differs from the peak position of free DMF at $1675 \mathrm{~cm}^{-1}$.

To assess the role of DMF complex, we performed synchrotron (In $\mathrm{L}_{3}$-edge) X-ray absorption near edge structures (XANES) (Fig. 2b). XANES features of In are not very sensitive to anion substitutions but to the coordination number ${ }^{33}$. $\mathrm{InBr}_{3}$-InAs films show a similar peak position as pure $\mathrm{InBr}_{3}$ films deposited from DMF solution, but a shift compared to that of OA-InAs films. The peak position difference suggests that $\mathrm{In}$ in $\mathrm{InBr}_{3}$-InAs and $\mathrm{InBr}_{3}$ have sixfold coordination (In connects to 6 atoms) whereas OA-InAs only has only fourfold coordination ${ }^{33}$. 
Considering the presence of DMF, its potential interactions with the passivants and the sixfold coordination of In, we calculated the stabilization energy of Br-/DMF and In-Br/DMF co-passivants. In the case of zinc-blende InAs structure, there are 1.5 DBs (electrons from As or holes from In) at (100) surfaces and $0.75 \mathrm{DBs}$ at (111) surfaces ${ }^{20}$. These sites are hard to passivate as the ligands can only provide an integer number of carriers. These results suggest a larger stabilization energy by adding DMF coordination for both In-rich and As-rich surfaces (Fig. 1, Supplementary Fig. 2-4). The lower surface energies through $\mathrm{Br} / \mathrm{In}-\mathrm{Br}+\mathrm{DMF}$ co-passivation suggest that the dangling bonds on InAs CQD surface are passivated by DMF complexes.

We carried out thermogravimetric analysis (TGA) (Fig. 2c) to study the stability of InAs CQDs and gain insights into the composition of the final CQD solids. We analyzed the decomposition of ligands and solvent at different temperatures for the exchanged CQDs comparing TGA traces of pure $\mathrm{InBr}_{3}, \mathrm{AA}$ $\mathrm{InBr}_{3}, \mathrm{OA}-\mathrm{InAs}$, and $\mathrm{InBr}_{3}-\mathrm{InAs}$ : the weight loss of $1 \%$ in the range from $50^{\circ} \mathrm{C}$ to $158^{\circ} \mathrm{C}$ is attributed to the free DMF solvent (boiling point $153^{\circ} \mathrm{C}$ ) in InBr3-InAs solids; the weight loss of $\approx 2.5 \%$ in the range from $162^{\circ} \mathrm{C}$ to $240^{\circ} \mathrm{C}$ is attributed to the DMF from the decomposition of DMF-InBrx complex; the weight loss of $\approx 3.5 \%$ in the range from $240^{\circ} \mathrm{C}$ to $340^{\circ} \mathrm{C}$ may be the $\mathrm{AA} / \mathrm{InBr}_{3}$ complex decomposition (similar to the decomposition of $\mathrm{AA}-\mathrm{InBr}_{3}$ ); the final weight loss of $\approx 36.5 \%$ from $340^{\circ} \mathrm{C}$ to $420^{\circ} \mathrm{C}$ is attributed to the decomposition of $\mathrm{InBr}_{3}$ and residual OA. The decomposition of DMF-InBr $\mathrm{D}_{\mathrm{x}}$ complex agrees with the $\mathrm{InBr}_{3}$-DMF co-passivation mechanism ${ }^{34}$.

We performed $\mathrm{InBr}_{3}$-DMF ligand exchange on OA-capped InAs (OA-InAs) CQDs. After ligand exchange, the In-to-As ratio is close to 1:1 (Fig. 2f) vs. 3:1 before exchange. This high In-to-As ratio of OA-InAs is attributed to the free In-oleate in the solution that was not removed during CQD purification, evidenced by the decreased In signal peak width after ligand exchange (Fig. 2d) and the high C-to-As ratio before exchange. After $\mathrm{InBr}_{3}$-DMF ligand exchange, the $\mathrm{C}$ :In ratio decreased to $\approx 2: 1$. Fig. 2e shows the As signal after ligand exchange without any As signal oxidized. The appearance of $\mathrm{N}$ and $\mathrm{Br}$ signal suggests the existence of DMF and $\mathrm{Br}$ - in $\mathrm{InBr}_{3}$-InAs films, supporting the results above.

Based on the successful ligand exchange, we characterized the absorption of CQDs before and after the ligand exchange in solution (Fig. 3a). OA-capped CQDs show an excitonic peak at $916 \mathrm{~nm}$ with a peak-to-valley ratio of $\approx 2.6$. After ligand exchange, the excitonic peak redshifts to $928 \mathrm{~nm}$ and the peakto-valley ratio decreases to $\approx 2.2$. This indicates that quantum confinement is preserved after exchange. 

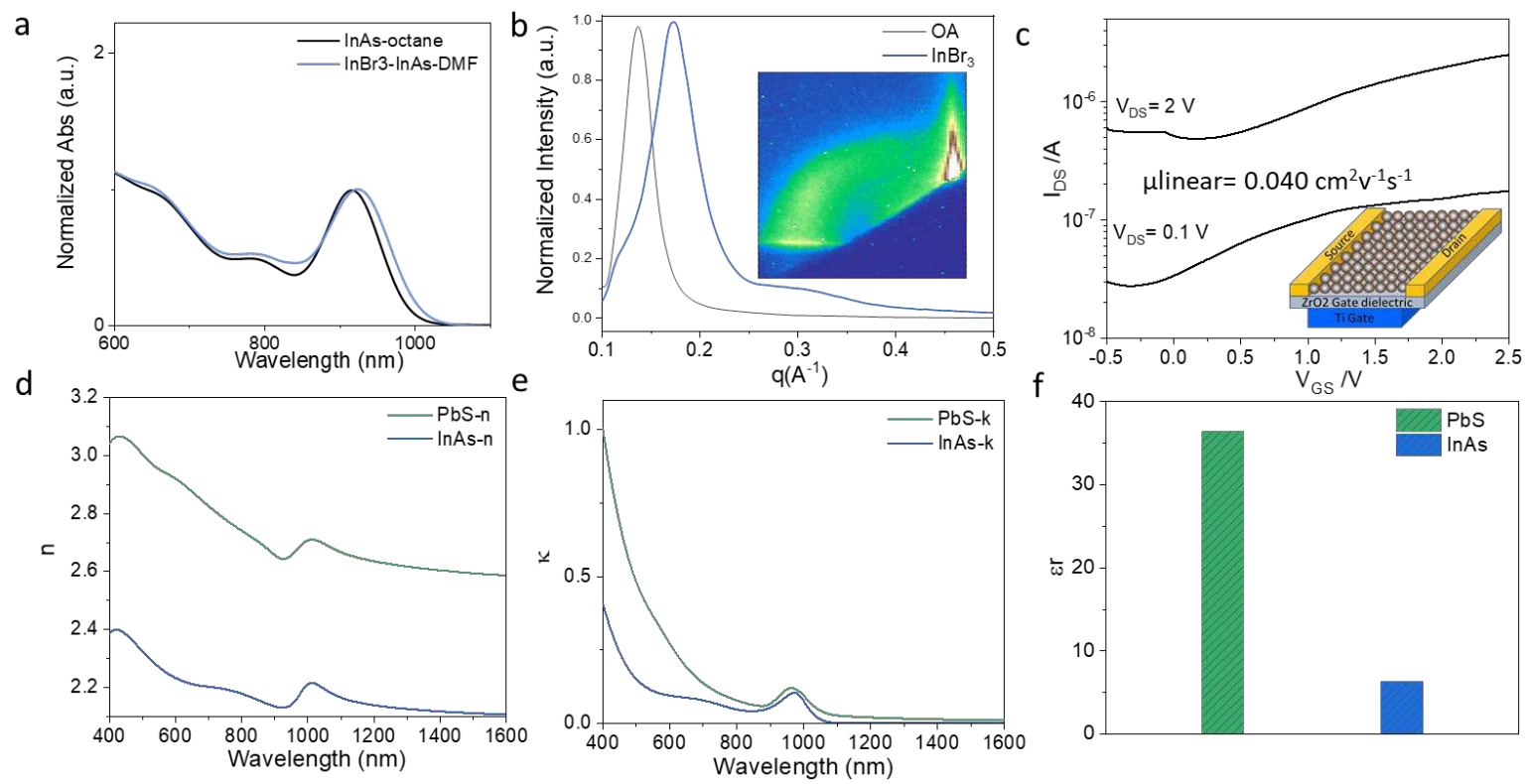

Fig. 3 | Improved transport properties and low dielectric constant of $\operatorname{InBr}_{3}-\mathrm{InAs}$ CQD films. a, Absorption of InAs CQD solution before and after ligand exchange. $\mathbf{b}$, Azimuthal integration of (GISAXS) patterns of InAs CQD films with GISAXS 2D pattern (inset) of InBr3-InAs CQD film. c, Transfer curves of $\operatorname{InBr}_{3}$-InAs CQD film in linear and saturation regimes with the field-effect transistor (FET) device structure (inset). d, The real and e, Imaginary refractive index of InAs compared to PbS QDs. f, Dielectric constant of $\operatorname{InBr}_{3}-\mathrm{InAs}$ and $\mathrm{PbI}_{2}-\mathrm{PbS} \mathrm{CQD}$ films.

To assess the interparticle distance and the necking produced after ligand exchange, we carried out grazing-incidence small-angle X-ray scattering (GISAXS) measurements (Fig. 3b). After $\operatorname{InBr}_{3}$ ligand exchange, the interdot distance decreased from $4.6 \mathrm{~nm}$ to $3.6 \mathrm{~nm}$, as extracted from the azimuthally integrated coherence peak. This is consistent with OA replacement by inorganic ligands.

To characterize charge transport in the exchange solid, we measured mobility using FET devices ${ }^{35}$. FET output characteristics reveal the n-type transport enhancement mode for $\mathrm{InBr}_{3}$-InAs CQD films (Supplementary Fig. 5). The carrier mobility is $0.032 \pm 0.003 \mathrm{~cm}^{2} \mathrm{~V}^{-1} \mathrm{~s}^{-1}$ in the linear regime $\left(\mu_{\text {lin }}\right)$ and $0.040 \pm 0.005 \mathrm{~cm}^{2} \mathrm{~V}^{-1} \mathrm{~s}^{-1}$ in the saturation regime $\left(\mu_{s a t}\right)$ is, (Fig. 3c), over 10 times higher than the two-step ligand exchange ${ }^{18}$. The current on/off ratio is only about 10, indicating that the thickness of the CQD layer exceeded the depth of the accumulation channel formed in the CQD solid upon applied gate bias and that the electron concentration is high in $\mathrm{InBr}_{3}-\mathrm{InAs}$ CQD solids. 
We extracted the carrier concentration through mobility and conductivity, obtaining a value of $1.11 \times 10^{17} \mathrm{~cm}^{-3}$ and $1.39 \times 10^{17} \mathrm{~cm}^{-3}$ from $\mu_{\text {lin }}$ and $\mu_{\text {sat }}$, respectively. This suggests that the $\mathrm{InBr}_{3}-\mathrm{InAs}$ CQD solids are n-type doped. We confirmed the n-type transport polarity of $\mathrm{InBr}_{3}$-InAs CQD films using ultraviolet photoelectron spectroscopy (UPS), which revealed a conduction band minimum (CBM) at $4.62 \mathrm{eV}$, a valance band maximum (VBM) at $-5.92 \mathrm{eV}$, and a Fermi level $\left(\mathrm{E}_{\mathrm{F}}\right)$ at $-4.79 \mathrm{eV}$ (Supplementary Fig. 8a). This agrees with the carrier concentration obtained from FET results.

To assess the optical properties of exchanged InAs films, we measured the complex refractive index and compared it with PbS CQD films for reference. We found that the real part of the refractive index is higher in PbS CQD films (Fig. 3d, 3e), which could be attributed to its higher permittivity. To characterize the dielectric constant at electrical frequencies, we measured the capacitance in a diode device configuration (Supplementary Fig. 6 and Fig. 3f). We obtained $\varepsilon_{\mathrm{r}}=34.8$ for PbS CQDs and a much lower value $\left(\varepsilon_{\mathrm{r}}=6.3\right)$ for InAs solids.

a

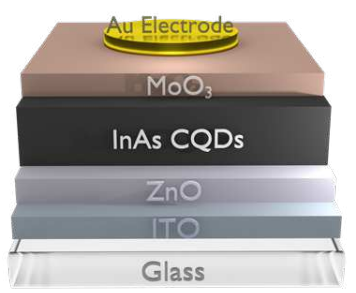

b
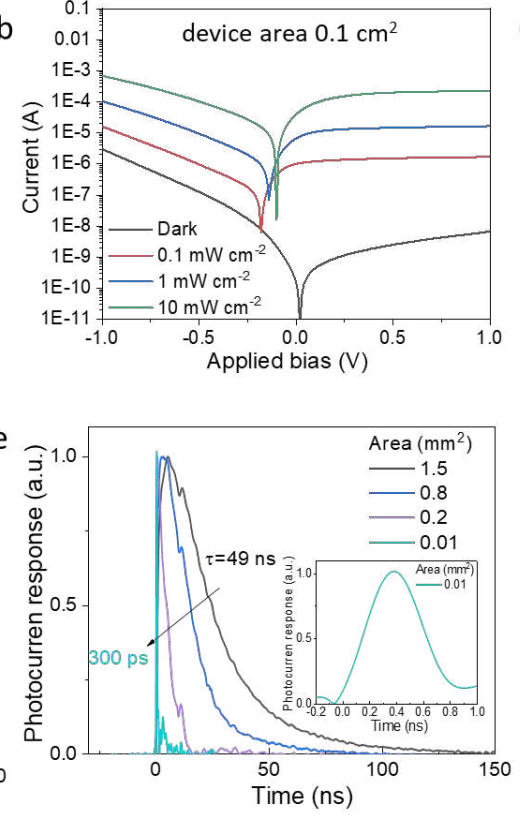
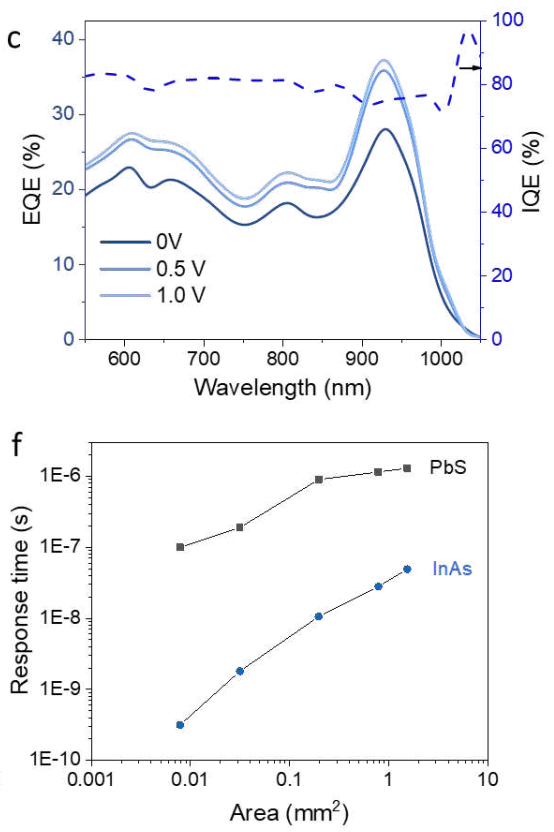

177

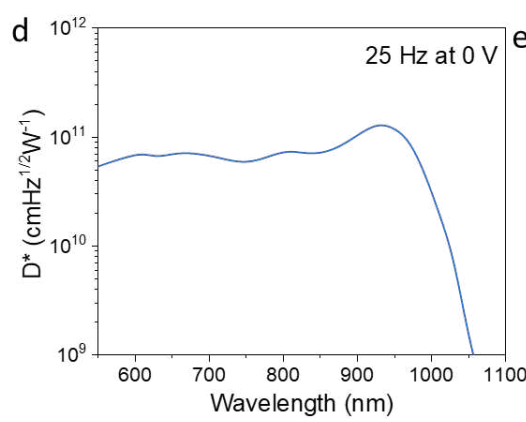

Fig. 4 | Fast photodetector using low- $\varepsilon$ InAs CQDs. a, Schematic of photodiode device structure. b, $I-V$ characteristics of $\mathrm{InBr}_{3}$-InAs CQD photodiodes dark and illuminated condition. c, External quantum efficiency (EQE) biased from 0 to $1 V$ and internal quantum efficiency (IQE, divide EQE (@ 0 V) by EQE (@ 1 V)). d, Detectivity of $\mathrm{InBr}_{3}$-InAs $\mathrm{CQD}$ photodiodes. e, Device area dependent response time of InBr3-InAs CQD photodiodes. f, 
Considering the energy levels of InAs CQD solids, we designed a device architecture consisting of ITO / ZnO / InAs / Au. Unfortunately, this arrangement resulted in poor diode behavior and high dark currents (Supplementary Fig. 7a). Reasoning that this structure may have produced back injection of electrons from InAs into $\mathrm{Au}$, we added a layer of $10 \mathrm{~nm}$ of $\mathrm{MoO}_{3}$ as an electron blocking layer between InAs and Au (Fig. 4a, Supplementary Fig. 8b). We observed a decrease in dark current by 3 orders magnitude to $\approx 70 \mathrm{nA} \mathrm{cm}^{-2}$ at $1.0 \mathrm{~V}$ reverse bias (Fig. 4b) accompanied by a significant increase in EQE from $9 \%$ to $30 \%$ at $0 \mathrm{~V}$ bias (Fig. 4c), a responsivity of $0.22 \mathrm{~A} \mathrm{~W}^{-1}$ (Supplementary Fig. 9) and measured detectivity of $10^{11} \mathrm{cmHz}^{1 / 2} \mathrm{~W}^{-1}$ at the excitonic peak (940 nm, Fig. 4d). This is the highest EQE reported for an InAs CQD photodetector.

We then characterized the time response of the InAs CQD photodiodes after ultrafast photoexcitation using $100 \mathrm{fs}$ laser pulses. We designed an electrical footprint that enables us to measure $\mathrm{EQE} / J V$ curves and incorporate small pixels with diameters from $1400 \mu \mathrm{m}$ to $100 \mu \mathrm{m}$ (Supplementary Fig. 10).

To assess the impact of device capacitance, we studied the response time for different pixel areas. The fall time decreases from $50 \mathrm{~ns}$ for $1.5 \mathrm{~mm}^{2}$ to $300 \mathrm{ps}$ for $0.01 \mathrm{~mm}^{2}$ pixels (Fig. 4e). The magnification of transient photocurrent spectra for the lowest pixel area is shown in the inset. PbS CQDs devices show a similar trend but $\approx 2$ orders of magnitude longer fall time compared to InAs diodes (Fig. 4f). This can be ascribed to the higher capacitance in $\mathrm{PbS}$ compared to InAs QDs. These results also suggest that we have not reached the mobility-limited transport regime even at the smallest pixel area, as fall time keeps decreasing with decreasing device area and does not reach a plateau (Fig. 4f).

We then measured the $-3 \mathrm{~dB}$ cut-off frequency using a vertical-cavity surface-emitting laser (VCSEL) light source modulated at different frequencies (Supplementary Fig. 11). The response stays constant until $25 \mathrm{MHz}$ and crosses $-3 \mathrm{~dB}$ at about $150 \mathrm{MHz}$ (Fig. 4f). TPC results for the same diameter pixel $\left(0.2 \mathrm{~mm}^{2}\right)$ reveal a fall time of $\approx 2 \mathrm{~ns}$, which would correspond to a $3 \mathrm{~dB}$ cut-off frequency of $\approx 175$ MHz. We note that due to the low power of the VCSEL and focusing limitations, we could not obtain cutoff frequency for smaller pixels. Based on the TPC decay of the fastest pixels, we can expect $\mathrm{a} \approx 1 \mathrm{GHz}$ bandwidth for $0.01 \mathrm{~mm}^{2}$ devices. 
209 In sum, we have introduced an amphoteric passivation strategy to co-passivate both In and As on InAs

210 CQD surfaces providing passivation and charge transport for low permittivity CQD solids. We revealed

211 the important role of DMF as a coordinating agent that stabilizes both X-and Z-type passivants.

212 Consequently, we were able to achieve for the first time efficient InAs CQDs photodiodes showcasing an

213 EQE of $\sim 30 \%$ at $0 \mathrm{~V}$ and a specific detectivity of $10^{11} \mathrm{cmHz}^{1 / 2} \mathrm{~W}^{-1}$ at the near-infrared. The low

214 permittivity and passivation of the InAs CQD solid result in a fall time of $300 \mathrm{ps}$, the fastest CQD

215 photodiode. Our findings open the door to the realization of high-performance optoelectronic devices

216 based on III-V CQDs. 


\section{References}

218 1. Caniou, J. Passive Infrared Detection: Theory and Applications. (2010).

$2192 . \quad$ Tan, C.L. \& Mohseni, H. Emerging technologies for high performance infrared detectors. 7, 169 (2018).

220 3. Hansard, M., Lee, S., Choi, O. \& Horaud, R.P. Time-of-Flight Cameras: Principles, Methods and Applications, 221 (Springer-Verlag London, 2011).

222 4. Hasch, J. Driving towards 2020: Automotive radar technology trends. in 2015 IEEE MTT-S International 223 Conference on Microwaves for Intelligent Mobility (ICMIM) 1-4 (2015).

$2245 . \quad$ Rogalski, A. History of infrared detectors. Opto-Electronics Review 20, 279-308 (2012).

225 6. Suzuki, T. Challenges of image-sensor development. in 2010 IEEE International Solid-State Circuits

7. Kagan, C.R., Lifshitz, E., Sargent, E.H. \& Talapin, D.V. Building devices from colloidal quantum dots. Science 353(2016).

8. Kovalenko, M.V. Opportunities and challenges for quantum dot photovoltaics. Nat Nanotechnol 10, 994-7 (2015).

9. Norris, D.J. Multispectral quantum-dot photodetectors. Nature Photonics 13, 230-232 (2019).

10. Kirmani, A.R., Luther, J.M., Abolhasani, M. \& Amassian, A. Colloidal Quantum Dot Photovoltaics: Current Progress and Path to GW-Scale Enabled by Smart Manufacturing. ACS Energy Letters (2020).

11. Saran, R. \& Curry, R.J. Lead sulphide nanocrystal photodetector technologies. Nature Photonics 10, 81-92 (2016).

12. McDonald, S.A. et al. Solution-processed PbS quantum dot infrared photodetectors and photovoltaics. Nat Mater 4, 138-42 (2005).

13. Burstein, E., Perkowitz, S. \& Brodsky, M. THE DIELECTRIC PROPERTIES OF THE CUBIC IV-VI COMPOUND SEMICONDUCTORS. (1968).

14. Zogg, H. et al. Infrared sensor arrays with 3-12 mu m cutoff wavelengths in heteroepitaxial narrow-gap semiconductors on silicon substrates. IEEE Transactions on Electron Devices 38, 1110-1117 (1991).

15. Clifford, J.P. et al. Fast, sensitive and spectrally tuneable colloidal-quantum-dot photodetectors. Nature Nanotechnology 4, 40-44 (2009).

16. Qiao, K. et al. Spectra-selective PbS quantum dot infrared photodetectors. Nanoscale 8, 7137-7143 (2016).

17. Fang, H. et al. Visible Light-Assisted High-Performance Mid-Infrared Photodetectors Based on Single InAs Nanowire. Nano Letters 16, 6416-6424 (2016).

18. Song, J.H., Choi, H., Pham, H.T. \& Jeong, S. Energy level tuned indium arsenide colloidal quantum dot films for efficient photovoltaics. Nat Commun 9, 4267 (2018).

19. Liu, W., Lee, J.S. \& Talapin, D.V. III-V nanocrystals capped with molecular metal chalcogenide ligands: high electron mobility and ambipolar photoresponse. J Am Chem Soc 135, 1349-57 (2013).

20. Kim, Y. et al. III-V colloidal nanocrystals: control of covalent surfaces. Chemical Science 11, 913-922 (2020).

21. Bae, W.K. et al. Controlled Alloying of the Core-Shell Interface in CdSe/CdS Quantum Dots for Suppression of Auger Recombination. ACS Nano 7, 3411-3419 (2013).

22. Speirs, M.J. et al. Origin of the increased open circuit voltage in PbS-CdS core-shell quantum dot solar cells. Journal of Materials Chemistry A 3, 1450-1457 (2015).

23. Scalise, E. et al. Surface chemistry and buried interfaces in all-inorganic nanocrystalline solids. Nature Nanotechnology 13, 841-848 (2018).

24. Fu, H. \& Zunger, A. InP quantum dots: Electronic structure, surface effects, and the redshifted emission. Physical Review B 56, 1496-1508 (1997).

25. Kirkwood, N. et al. Finding and Fixing Traps in II-VI and III-V Colloidal Quantum Dots: The Importance of ZType Ligand Passivation. Journal of the American Chemical Society 140, 15712-15723 (2018).

26. Xu, Q. et al. Ultrafast Colloidal Quantum Dot Infrared Photodiode. ACS Photonics 7, 1297-1303 (2020).

27. Sagar, L.K. et al. Single-Precursor Intermediate Shelling Enables Bright, Narrow Line Width InAs/InZnP-Based QD Emitters. Chemistry of Materials 32, 2919-2925 (2020).

28. Tamang, S., Lee, S., Choi, H. \& Jeong, S. Tuning Size and Size Distribution of Colloidal InAs Nanocrystals via Continuous Supply of Prenucleation Clusters on Nanocrystal Seeds. Chemistry of Materials 28, 8119-8122 (2016). 
29. Mićić, O.I., Sprague, J., Lu, Z. \& Nozik, A.J. Highly efficient band-edge emission from InP quantum dots. 68, 3150-3152 (1996).

30. Hartley, C.L. \& Dempsey, J.L. Electron-Promoted X-Type Ligand Displacement at CdSe Quantum Dot Surfaces. Nano Letters 19, 1151-1157 (2019).

31. Stein, J.L., Mader, E.A. \& Cossairt, B.M. Luminescent InP Quantum Dots with Tunable Emission by PostSynthetic Modification with Lewis Acids. The Journal of Physical Chemistry Letters 7, 1315-1320 (2016).

32. Liu, M.X. et al. Controlled Steric Hindrance Enables Efficient Ligand Exchange for Stable, Infrared-Bandgap Quantum Dot Inks. Acs Energy Letters 4, 1225-1230 (2019).

33. T-Thienprasert, J., Rujirawat, S., Nukeaw, J. \& Limpijumnong, S. X-ray absorption spectroscopy of indium nitride, indium oxide, and their alloys. Computational Materials Science 49, S37-S42 (2010).

34. Dong, A. et al. A Generalized Ligand-Exchange Strategy Enabling Sequential Surface Functionalization of Colloidal Nanocrystals. Journal of the American Chemical Society 133, 998-1006 (2011).

35. Sun, B. et al. Pseudohalide-Exchanged Quantum Dot Solids Achieve Record Quantum Efficiency in Infrared Photovoltaics. Adv Mater 29, 1700749 (2017).

36. Lüssem, B. et al. Doped Organic Transistors Operating in the Inversion and Depletion Regime. Nat Commun 4, 2775 (2013).

\section{Methods}

Materials. All the chemicals are purchased from commercial suppliers and used as received. Suppliers disclaimer: "Certain commercial equipment, instruments, or materials are identified in this paper to specify the experimental procedure adequately. Such identification is not intended to imply recommendation or endorsement by the National Institute of Standards and Technology, nor is it intended to imply that the materials or equipment identified are necessarily the best available for the purpose."

InAs CQDs Synthesis, InAs QDs were synthesized using a modified approach via the continuous injection by reacting $\mathrm{In}(\text { oleate })_{3}$, tris(trimethylgermyl)arsine ((TMGe) $\left.)_{3} \mathrm{As}\right)$ under an $\mathrm{N}_{2}$ atmosphere at $300^{\circ} \mathrm{C}$ using a modified approach ${ }^{27,28}$.

Device fabrication. The $\mathrm{InBr}_{3} / \mathrm{AA}$ solution-phase ligand-exchange process was carried out in a test tube in an $\mathrm{N}_{2}$-filled glovebox. $\operatorname{InBr}_{3}\left(0.1 \mathrm{molL}^{-1}, 0.18 \mathrm{~g}\right)$ and ammonium acetate $\left(0.04 \mathrm{molL}^{-1}, 0.023 \mathrm{~g}\right)$ are predissolved in $5 \mathrm{~mL}$ of dimethylformamide (DMF). A $5 \mathrm{ml}$ amount of CQD octane solution $\left(10 \mathrm{mg} \mathrm{ml}^{-1}\right)$ was added to $5 \mathrm{ml}$ of the precursor solution. These were vortexed for 1-2 min until the CQDs completely transferred to the DMF phase, followed by washing three times with octane. After ligand exchange, CQDs were precipitated via the addition of toluene $(\sim 10 \mathrm{~mL})$ and separated by centrifugation. After $10 \mathrm{~min}$ of vacuum drying, the CQDs were then redispersed in DMF $\left(200 \mathrm{mg} \mathrm{m}^{-1}\right)$ to form the film on $\mathrm{ZnO}$ nanoparticle coated ITO substrate by spin-coating at (1000 to 2000) rpm. Finally, $100 \mathrm{~nm}$ of Au was thermally deposited as a back electrode. 
X-Ray Photoelectron Spectroscopy (XPS). XPS spectra were measured in $\mathrm{N}_{2}$ by using a Thermo Scientific K-Alpha System with an Al K $\alpha$ source. The films were spin-coated on Si substrates. Scans were taken in $0.05 \mathrm{eV}$ steps with a $50 \mathrm{eV}$ pas energy. The atomic ratios were obtained by integrating under the area of each peak and scaled by atomic sensitivity factors. We normalized all of the element areas with respect to As to obtain accurate atomic ratios.

Fourier transform infrared (FTIR) spectroscopy measurements. FTIR measurements were performed on a Bruker Vertex $80,(8000$ to 600$) \mathrm{cm}^{-1}$; resolution $4 \mathrm{~cm}^{-1}$, in top-configuration (attenuated total reflection, ATR).

Absorption Measurements. The optical absorption measurements were performed with a Perkin-Elmer Lambda 950 UV-Vis-NIR spectrophotometer. The solutions were placed in a quartz cuvette with a $1 \mathrm{~mm}$ path length.

Transmission electron microscopy measurements (TEM). TEM images were acquired on a Hitachi HF 3300 electron microscope operating at $300 \mathrm{keV}$. TEM samples were prepared by drop-casting a purified solution of CQDs from n-octane onto a 300 mesh copper grid with a carbon film (SPI supplies).

X-ray scattering measurements. Grazing incidence small-angle X-ray scattering (GISAXS) samples were prepared by spin-coating a layer of InAs film following the same procedure as the device fabrication on a Si substrate. The measurements were carried out at the CMS beamline of the National Synchrotron Light Source II, a U.S. Department of Energy (DOE) office of the Science User Facility operated for the DOE Office of Science by Brookhaven National Laboratory. GISAXS images were collected with an imaging detector at a distance of $0.178 \mathrm{~m}$ using X-ray wavelength of $1.033 \AA$. Nika software package was used to sector average the 2D GISAXS images. Data plotting was done in Igor Pro (Wavemetrics, Inc., Lake Oswego, OR, USA). 
Thermal gravimetric analysis measurement (TGA). TGA measurements were conducted using a PerkinElmer Pyris 1 TGA. About (6 to 8) mg of quantum dot solids were taken on a platinum pan. An equilibration or isothermal step at $50{ }^{\circ} \mathrm{C}$ for $15 \mathrm{~min}$ and later heated to $800{ }^{\circ} \mathrm{C}$ with a heating rate of $10^{\circ} \mathrm{C} /$ min were carried out under nitrogen. The residual weight of InAs QDs after $780^{\circ} \mathrm{C}$ increased from $37 \%$ to $56 \%$ after ligand exchange, which confirms the reduced amount of organic ligands as OA was replaced. We also analyzed the decomposition of ligands and solvent at different temperatures for the exchanged CQDs comparing TGA traces of pure $\mathrm{InBr}_{3}$, AA- $\mathrm{InBr}_{3}$, OA-InAs, and $\mathrm{InBr}_{3}-\mathrm{InAs}_{\text {A }}$ The weight loss of $1 \%$ in the range from $50{ }^{\circ} \mathrm{C}$ to $158{ }^{\circ} \mathrm{C}$ is attributed to the free DMF solvent (boiling point $153{ }^{\circ} \mathrm{C}$ ) in InBr3-InAs solids; the weight loss of $\approx 2.5 \%$ in the range from $162{ }^{\circ} \mathrm{C}$ to $240{ }^{\circ} \mathrm{C}$ is attributed to the DMF from the decomposition of DMF-InBrx complex; the weight loss of $\approx 3.5 \%$ in the range from $240{ }^{\circ} \mathrm{C}$ to 340 ${ }^{\circ} \mathrm{C}$ may be the $\mathrm{AA} / \mathrm{InBr}_{3}$ complex decomposition (similar to the decomposition of $\mathrm{AA}-\mathrm{InBr}_{3}$ ); the final weight loss of $\approx 36.5 \%$ from $340^{\circ} \mathrm{C}$ to $420{ }^{\circ} \mathrm{C}$ is attributed to the decomposition of $\mathrm{InBr}_{3}$ and residual OA.

FET fabrication. Bottom-gate top-contact FET configuration is used as follows: $70 \mathrm{~nm}$ of titanium (Ti) gate was thermally evaporated onto a glass substrate, followed by $15 \mathrm{~nm}$ of $\mathrm{ZrO} 2$ as a dielectric layer using atomic layer deposition (ALD). After $300^{\circ} \mathrm{C}$ baking for 1 hour, the pre-exchanged InAs CQDs dissolved in DMF was spin-coated onto the substrate. Then $70 \mathrm{~nm}$ of $\mathrm{Au}$ source/drain electrodes were thermally deposited using an Angstrom Engineering Amod deposition system. Agilent semiconductor analyzer was used to characterize the FET devices. We calculated carrier mobility from the slope of the drain-source current $\left(I_{D S}\right)$ vs. gate voltage $\left(V_{G S}\right)$ according to the equation $\mathrm{I}_{\mathrm{DS}}=\frac{\mu_{\mathrm{lin}} \mathrm{C}_{\mathrm{i}} \mathrm{W}}{\mathrm{L}}\left(\mathrm{V}_{\mathrm{GS}}-\mathrm{V}_{\mathrm{TH}}\right) \mathrm{V}_{\mathrm{DS}} \quad(1)$ and $\mathrm{I}_{\mathrm{DS}}=\frac{\mu_{\mathrm{sat}} \mathrm{C}_{\mathrm{i}} \mathrm{W}}{2 \mathrm{~L}}\left(\mathrm{~V}_{\mathrm{GS}}-\mathrm{V}_{\mathrm{TH}}\right)^{2}(2)$, where $\mu_{\text {lin }}$ and $\mu_{\text {sat }}$ are the carrier mobility in the linear regime and saturation regime, respectively; $I_{D S}$ is the drain-source current; $L$ and $W$ are the channel length $(50 \mu \mathrm{m})$ and channel width $(2.5 \mathrm{~mm})$ respectively; $\mathrm{Ci}$ is the capacitance per area $\left(450 \mathrm{nF} \mathrm{cm} \mathrm{cm}^{-2}\right)$, and $V_{G S}$ and $V_{T H}$ are the gate voltage and threshold voltage, respectively. We also obtained the carrier density following the formula

$$
\sigma=\mathrm{L} /(\mathrm{RA})(3) \text { and } \mathrm{n}=\sigma /(\mathrm{q} \mu)(4)
$$

where $\sigma$ is the conductivity; $\mathrm{L}$ is channel length; $\mathrm{R}$ is the resistance of the device; $\mathrm{A}$ is the cross area of the film between source and drain electrodes; $\mathrm{n}$ is the carrier concentration (electron concentration in this test); $\mathrm{q}$ is the elementary charge; $\mu$ is the mobility. 
Ultraviolet photoelectron spectroscopy (UPS) measurement. A CQD film on indium tin oxide (ITO) glass on was measured in a PHI5500 Multi-Technique system with a base pressure of $\sim 10^{-9}$ Torr and the Fermi energy calibrated to $0 \mathrm{eV}$. A helium discharge source $(\mathrm{HeI} \alpha, \mathrm{hv}=21.22 \mathrm{eV}$ ) was used and the samples were kept at a take-off angle of $88^{\circ}$. During measurement, the sample was held at a $-15 \mathrm{~V}$ bias relative to the spectrometer to efficiently collect low-kinetic energy electrons. Fermi level $\left(\mathrm{E}_{\mathrm{F}}\right)$ was calculated from the equation: $E_{F}=21.22 \mathrm{eV}-\mathrm{SEC}$, where SEC is the Secondary Electron Cut-off. The difference between VBM level and Fermi level, $\eta$, was determined from VBM onset in the VBM region ${ }^{36}$.

Photodiode fabrication. The ITO glass substrates were cleaned by sonication in acetone and isopropanol for $30 \mathrm{~min}$ each. After drying, the $\mathrm{ZnO}$ nanoparticle via sol-gel method using Zinc acetate dihydrate $\left(\mathrm{Zn}\left(\mathrm{CH}_{3} \mathrm{COO}\right)_{2} .2 \mathrm{H}_{2} \mathrm{O}\right)$ as a precursor in ethanol $\left(\mathrm{CH}_{3} \mathrm{CH}_{2} \mathrm{OH}\right)$ and spin-coated onto ITO glass substrates at $2000 \mathrm{rpm}$ for $30 \mathrm{~s}$, followed by $340{ }^{\circ} \mathrm{C}$-annealing in air for $40 \mathrm{~min}$. Then $\mathrm{InBr}_{3}$-InAs CQDs in DMF (200mg $\mathrm{mL}-1$ ) was spin-coated on the substrate. The photodetector was finalized by sequential deposition of $10 \mathrm{~nm}$ of $\mathrm{MoO} 3$ and $120 \mathrm{~nm}$ of $\mathrm{Au}$ that serves as the top electrode. The photodetector area was described in Supplementary Fig. 10.

\section{Data availability}

The data that support the plots within this paper and other findings of this study are available from the corresponding author upon reasonable request.

\section{Acknowledgements}

\section{Funding}

We acknowledge funding from NSERC Discovery Grant and Canada Research Chair. This research used resources of the National Synchrotron Light Source II, which is a U.S. Department of Energy (DOE) Office of Science Facility, operated at Brookhaven National Laboratory under contract no. DESC0012704.

\section{Author Contributions}

B.S., A.M.N., C.Z., L.K.S., and M.J.C. contributed equally to this work. B.S. and F.P.G.A. conceived the idea of this study. B.S. developed the CQD passivation system. A.M.N. carried out the device time response measurements. C.Z. and O.V. performed the simulation studies. L.K.S. and L.L. synthesized the CQDs. M.J.C. did the EQE and dark current measurements. X.L. did the ligand exchange. B.S., L.K.S., X.L., S.W. B., S. L., J. A., and M. L. carried out material characterization and device fabrication. A.R.K. and L.J.R carried out GIWAXS measurements. P. L. and Z. H. L. performed UPS measurements, F.P.G.A. and E.H.S. 
384 supervised the project. B.S., A.M.N., C.Z., F.P.G.A., and E.H.S. wrote the manuscript. All authors discussed 385 the results and assisted in the preparation of the manuscript.

\section{Competing Interests}

387 The authors declare no competing financial interests.

$388 \quad$ Additional information

389 Supplementary information is available for this paper at XXX. 
Figures

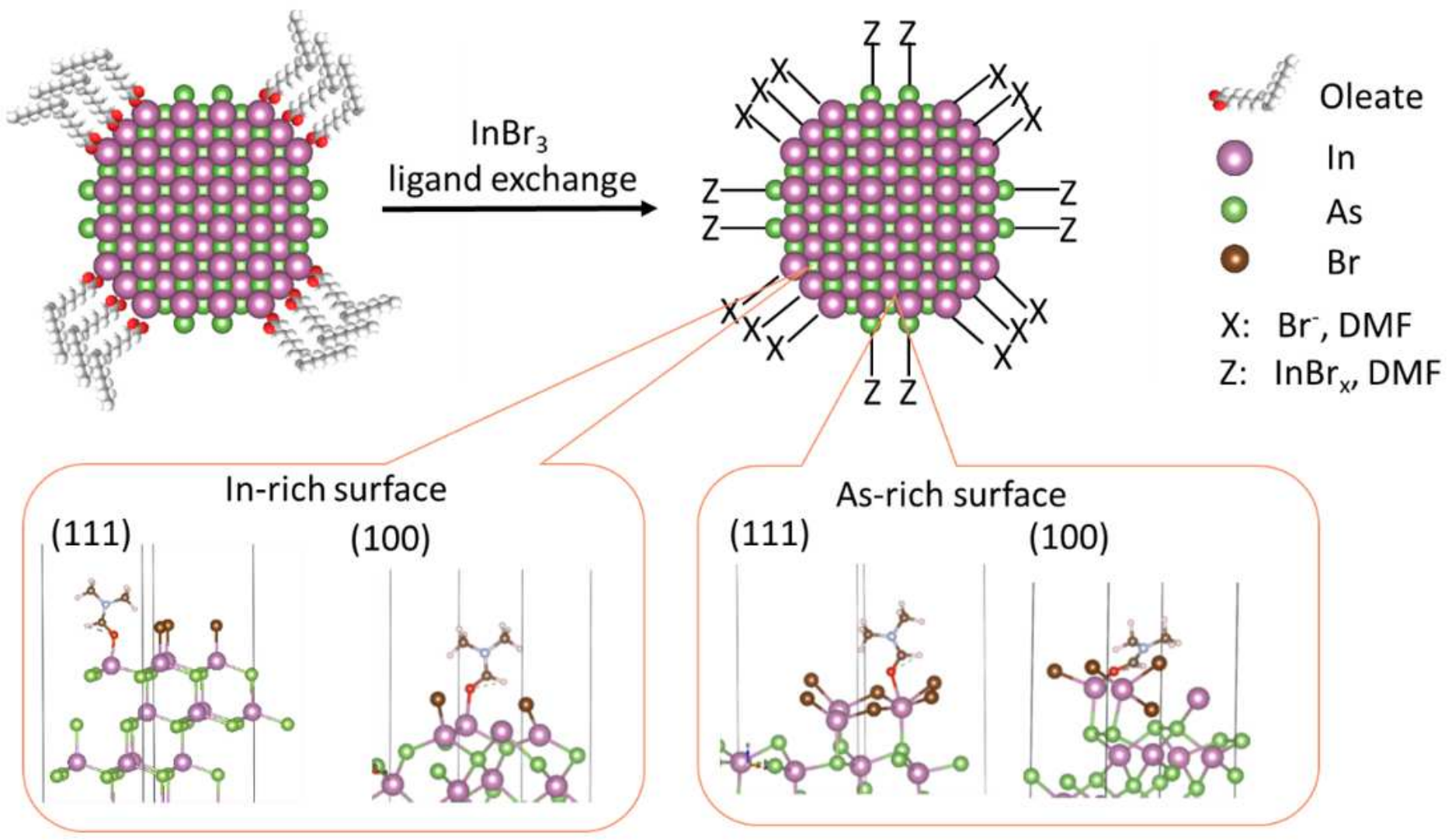

Figure 1

Stabilization of InAs CQDs. Scheme of InBr3 ligand exchange and InAs quantum dot surface configuration according to DFT calculations: a larger stabilization energy was observed by adding DMF coordination in the system for both In-rich and As-rich surfaces. 

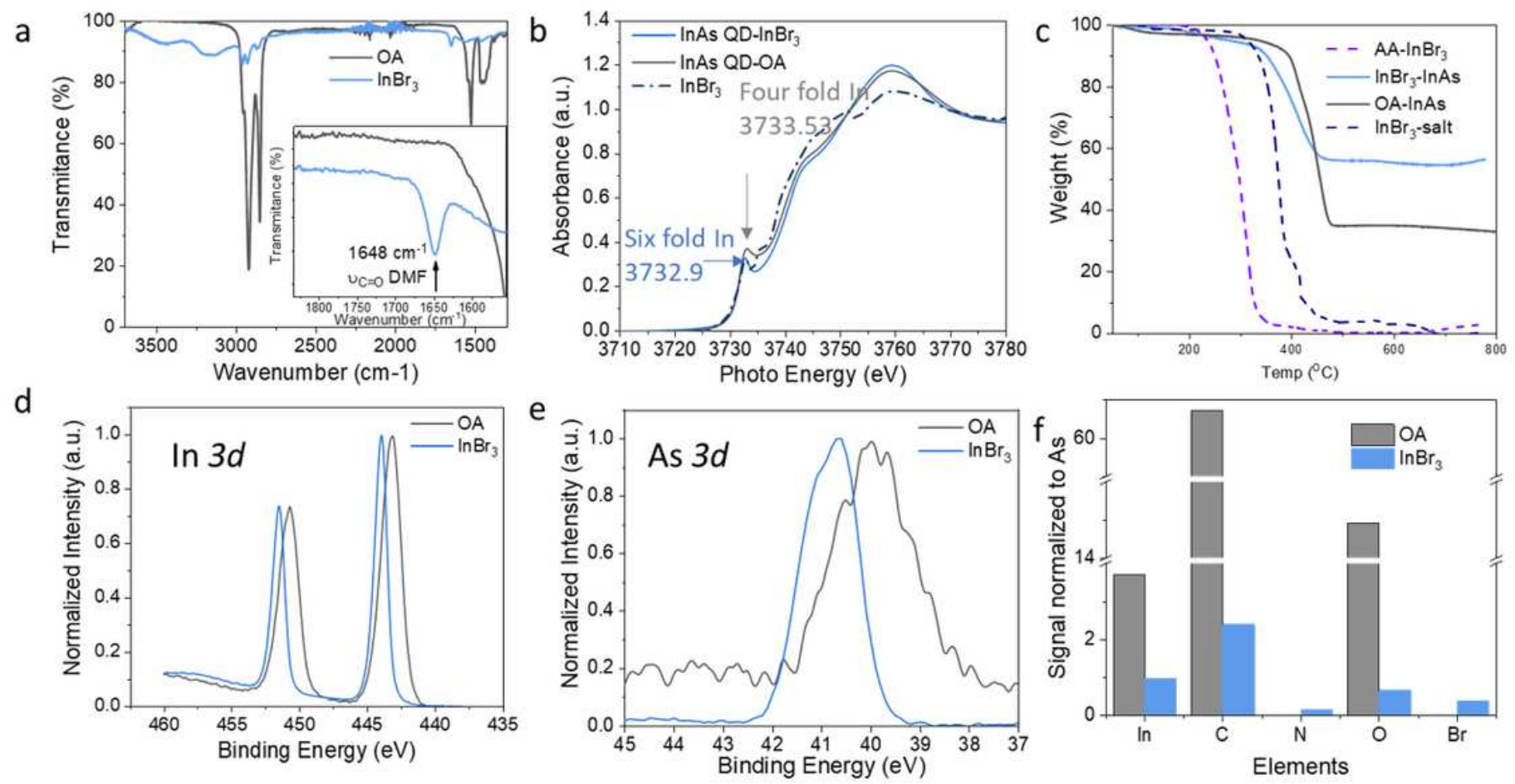

\section{Figure 2}

Investigation of passivation using InBr3-DMF complexes. a, Attenuated total reflection (ATR) FTIR of InAs CQD films before and after InBr3 ligand exchange on glass. b, In L3-edge XANES spectra of InAs CQD films and InBr3 films (spin-coated from DMF solution) on Si wafer. c, Thermogravimetric analysis (TGA) of InAs CQDs and InBr3 salt with/without AA samples. $d$, In 3d X-ray photoelectron spectroscopy (XPS) signal. e, As 3d XPS signal. f, Elemental ratio of InAs CQD films before and after InBr3 ligand exchange. 

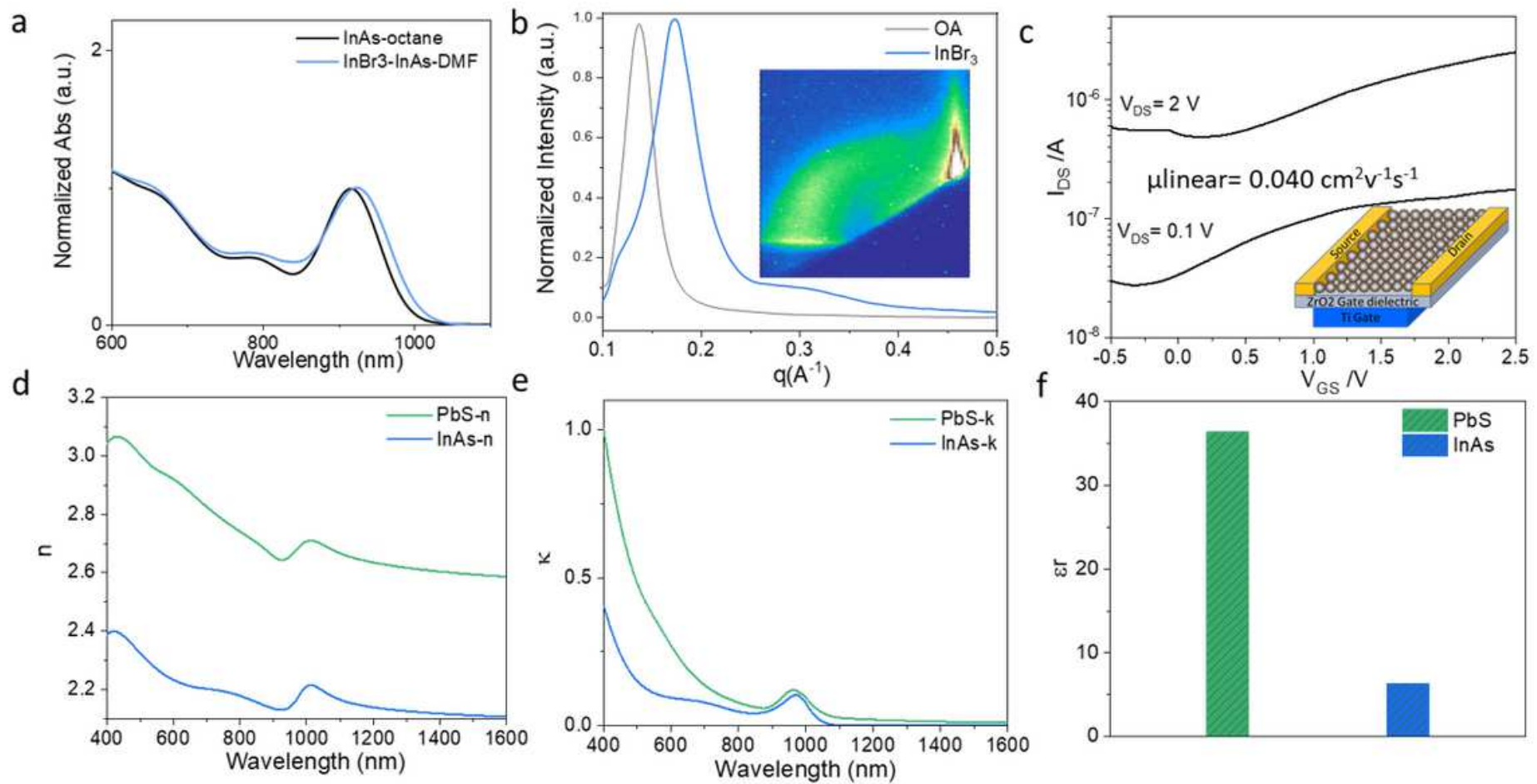

\section{Figure 3}

Improved transport properties and low dielectric constant of InBr3-InAs CQD films. a, Absorption of InAs CQD solution before and after ligand exchange. b, Azimuthal integration of (GISAXS) patterns of InAs CQD films with GISAXS 2D pattern (inset) of InBr3-InAs CQD film. C, Transfer curves of InBr3-InAs CQD film in linear and saturation regimes with the field-effect transistor (FET) device structure (inset). $d$, The real and e, Imaginary refractive index of InAs compared to PbS QDs. f, Dielectric constant of InBr3-InAs and Pbl2-PbS CQD films. 
a

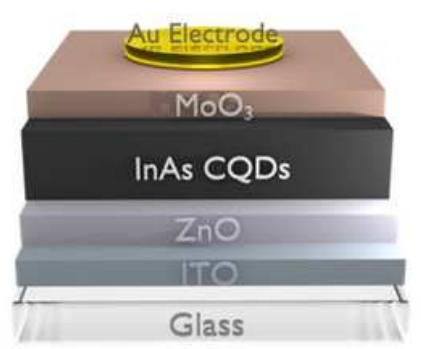

b

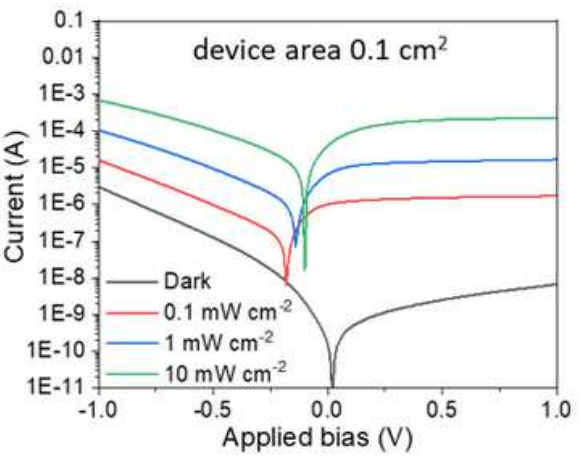

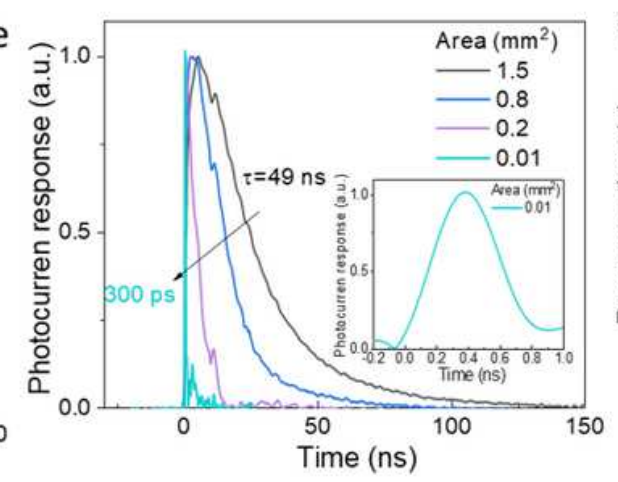
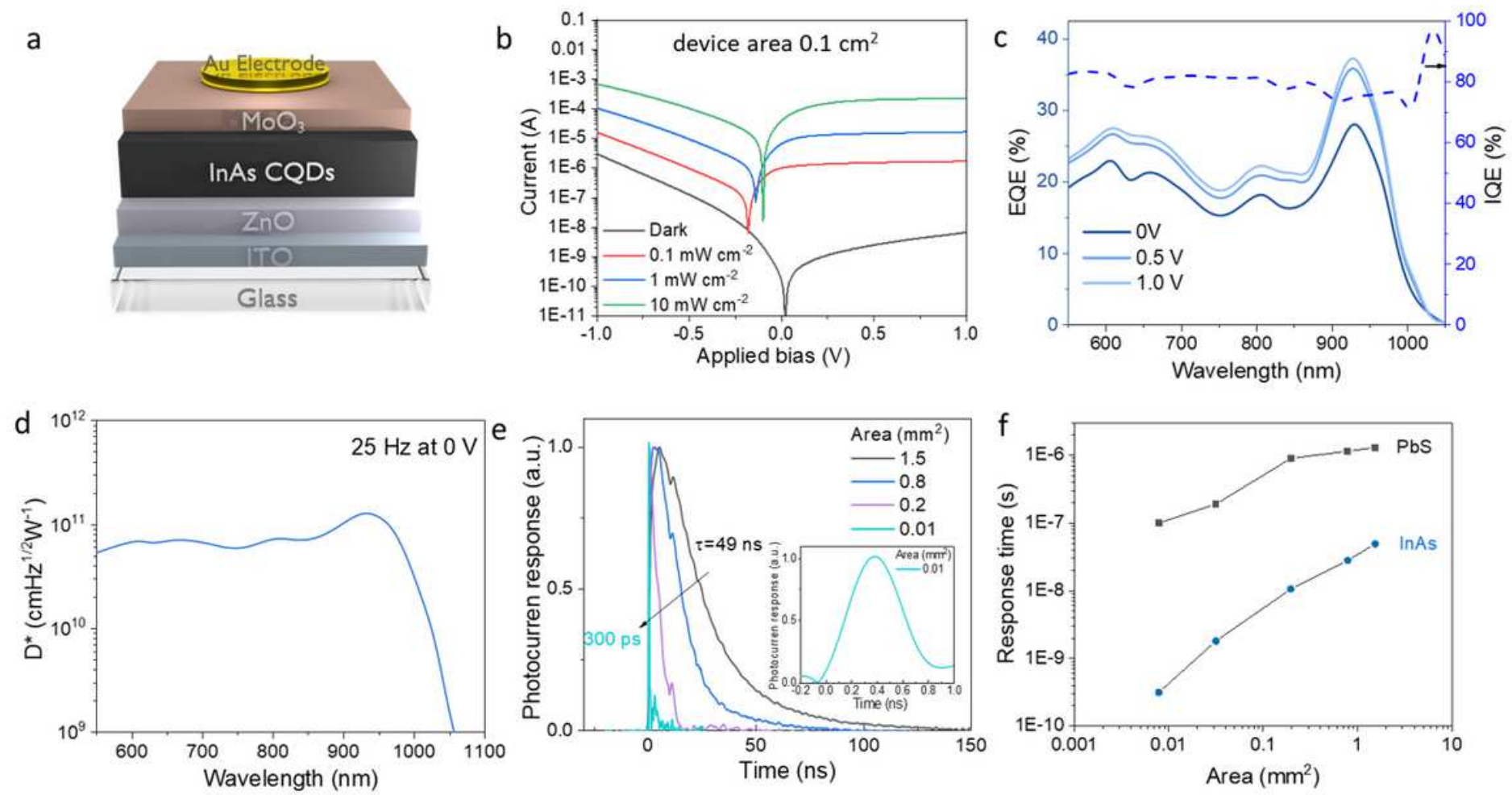

Figure 4

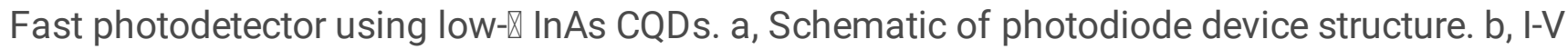
characteristics of InBr3-InAs CQD photodiodes dark and illuminated condition. c, External quantum efficiency (EQE) biased from 0 to 1 V and internal quantum efficiency (IQE, divide EQE (@ 0 V) by EQE (@ $1 \mathrm{~V})$ ). d, Detectivity of InBr3-InAs CQD photodiodes. e, Device area dependent response time of InBr3-InAs CQD photodiodes. $\mathrm{f}$, Comparison of the response time of devices with InAs CQD and PbS CQD films with different device areas.

\section{Supplementary Files}

This is a list of supplementary files associated with this preprint. Click to download.

- SI20201012.docx 